\title{
More Similar to My Father, Better Academic Performance I Will Have: The Role of Caring Parenting Style
}

\section{Mengjie Tu' \\ Yafei Guo ${ }^{2}$ \\ Xincai Zhang ${ }^{3}$ \\ Quanlei $\mathrm{Yu}^{1,4}$}

'School of Psychology, Central China Normal University, Wuhan, Hubei, People's Republic of China; ${ }^{2}$ Department of Business Administration, University of Illinois at Urbana-Champaign, Champaign, IL, USA; ${ }^{3}$ Fuyang City No.I I Middle School, Anhui, People's Republic of China; ${ }^{4}$ School of Psychology, Beijing Normal University, Beijing, People's Republic of China
Correspondence: Quanlei Yu Email yuleil9881987@mail.ccnu.edu.cn
Background: Parent-child facial resemblance, as an important cue of paternal uncertainty, may impact fathers' parenting behaviors and further affect children's academic performance. However, mothers are almost $100 \%$ confident of the blood relationship with their child and care less about the facial resemblance cues.

Methods: To test these hypotheses, the present study recruited 122 junior high school students and measured the perceived facial resemblance with their parents, the parents' parenting style, academic performance, and demographic variables.

Results: The results showed that the perceived father-child facial resemblance rather than the mother-child facial resemblance significantly influenced adolescents' academic performance. Further, fathers' caring parenting style mediated the relationship between the perceived father-child facial resemblance and academic performance.

Conclusion: These findings not only supported the paternal uncertainty hypothesis but also extended the parental investment theory.

Keywords: perceived father-child facial resemblance, academic performance, caring parenting, paternal uncertainty

\section{Introduction}

Due to the internal fertilization, women could be almost $100 \%$ sure that they had a genetic relationship with their offspring. In early human society, adultery practices were not uncommon and wives may secretly commit adultery with other men during the marriage, ${ }^{1}$ thus, men face the risk that putative children may not be their biological children, namely paternal uncertainty. ${ }^{2}$

In the process of human evolution, men have developed a series of adaptation mechanisms to identify the certainty of paternity. ${ }^{3}$ In daily life, men unconsciously seek cues that characterize their genetic identity to assess their paternal certainty. These cues include facial resemblance, ${ }^{4-6}$ body odor resemblance ${ }^{4}$ and perceived sexual loyalty of spouse. ${ }^{7-9}$ Among these cues, the facial resemblance between parents and children is the most accessible direct cue. ${ }^{5,7}$ Studies have shown that facial resemblance between two blood-related individuals is significantly higher than that of two unrelated individuals. ${ }^{6,10,11}$ Therefore, researchers often adopt father-child facial resemblance as one of the indicators to measure the paternity. $4,5,7,12,13$

According to the theory of inclusive fitness, nature was prone to select the characteristics that could promote the success in passing on genes, no matter whether the 
organism was direct descendant or genetic relative. ${ }^{14}$ Moreover, Trivers proposed that parents would invest resources to help offspring develop better, and to facilitate the spreading of their own genes. ${ }^{2}$ In fact, parents would invest more resources in parenting if the offspring provide a higher reproductive value, suggesting a higher possibility of successful gene transfer. ${ }^{15-17}$ If males invest his limited resources on the descendants of other males, it will impair their own inclusive fitness. ${ }^{2,14}$ Thus, in order to ensure their own inclusive fitness, men would adjust their investments and parenting behaviors during parenthood on the basis of the paternity certainty cues, ${ }^{11,17-19}$ including the father-child facial resemblance. ${ }^{5-7,20,21}$

Several empirical studies have demonstrated that when the father-child facial resemblance was high, fathers would adopt the positive parenting style and invest more on their children for the interest of the reproductive success rate. $5,7,22$ However, when the father-child facial resemblance was low, fathers would invest less on the development of their children because they did not want to waste their resources for children who may not pass on their genes. ${ }^{23,24}$ As Yu et al have found father-child facial resemblance affected the caring (supportive/engaged) parenting but not the control (hostile/coercive) parenting, ${ }^{24}$ for the latter parenting could not increase the rate of reproductive success. ${ }^{23}$

The amount of material and psychological resources that fathers invest in their offspring, which can be affected by the cues signaling paternal certainty, are vital to offspring's survival and growth. ${ }^{4,5,25}$ Studies have shown that father's parenting behaviors, for instance, warmth, communication, emotional support and proper autonomy, can have a positive impact on the child development. ${ }^{26-29}$ For example, Turner et al found that children with more autonomy and parental care had better academic performance. ${ }^{30}$ In fact, paternal care and emotional warmth could encourage children to correct mistakes, develop abilities and build confidence. ${ }^{31}$ As a result, children having paternal care and emotional support may end up having a positive self-concept, higher sense of responsibility, ${ }^{32}$ and better emotional skills to explore themselves in the society. ${ }^{33}$ These consequences in turn contribute to the children's enhanced academic performance. Previous studies also have found that children, whose parents adopt positive parenting style, are relatively more successful in achieving goal orientation and showing higher social responsibility and cooperation, ${ }^{26}$ which could predict children's academic performance. ${ }^{34}$

Rested upon the above literature, the current study presumes that the perceived father-child facial resemblance may affect the father's caring parenting, rather than father's control parenting, which further promote the children's academic performance. Meanwhile, since mothers can be almost $100 \%$ sure of the blood relationship with the offspring, they would not be affected by the perceived motherchild facial resemblance. In sum, this study hypothesizes that the caring factor in the parenting style mediates the relationship between the perceived parent-child facial resemblance and the child's academic performance, and the parents' sex moderates this mediation model (see the model in Figure 1).

There are three paradigms to explore the facial resemblance: manipulation method using the Morph software synthesis, ${ }^{35-38}$ third-party rating ${ }^{10,39}$ and self-rating. ${ }^{5,24,40}$ Among these three paradigms, the internal validity is highest for the manipulation method, and the ecological validity is highest for the self-rating method. ${ }^{40}$ To obtain the highest ecological validity, this study adopted the selfrating method to evaluate the parent-child facial resemblance. However, previous studies showed that some biases might confound the effects of the parent-child facial resemblance when it was measured by parents' selfreport. $^{5,40}$ On the one hand, fathers tend to be affected by self-serving bias, with the desirable belief that children look more like themselves. ${ }^{24}$ On the other hand, to assist their offspring obtaining more resources from the fathers, mothers are prone to admit that children look like their fathers, especially when fathers are present. ${ }^{5,19,41}$ To preclude these biases, this study used junior high school

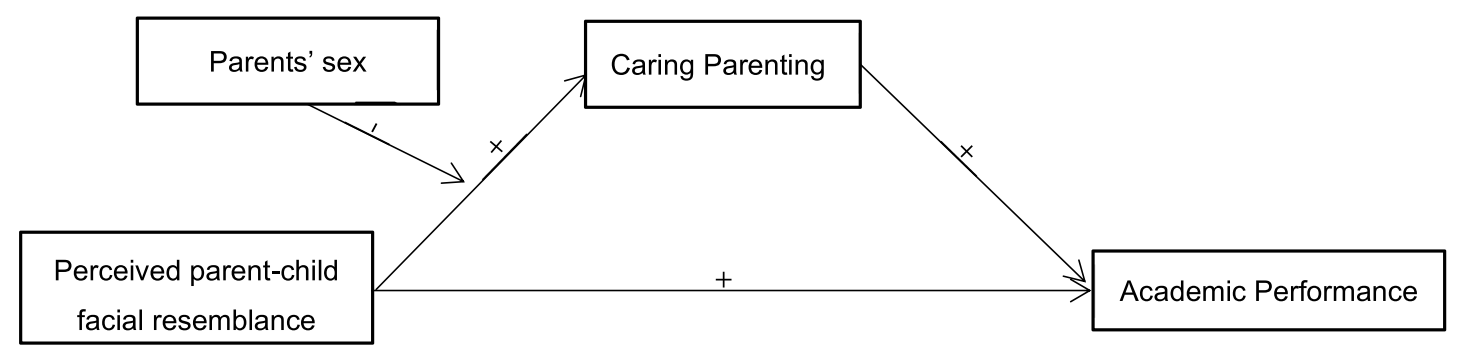

Figure I The influence mechanism of perceived parent-child facial resemblance on academic performance. 
students as the participants to explore the mediation of the parenting style and the moderation of the parent sex among the relationship between the perceived parentchild facial resemblance and the child's academic performance. Besides, previous studies have demonstrated that academic achievement could be affected by child's sex, ${ }^{42}$ child's age, ${ }^{43}$ parents' education ${ }^{44}$ and family economic status. ${ }^{42,45}$ To eliminate the confounding effects of these, this study included these variables as control variables.

\section{Method}

\section{Participants}

A total of 137 students were recruited as participants from a high school in Fuyang City, Anhui Province, China. After removing the data of 15 participants who came from non-intact families, 122 students remained in this study. Among them, 59 were boys, 62 were girls, and one participant's sex information was missing. The mean age was 14.14 years old $(S D=4.96)$.

\section{Measures}

\section{Perceived Parent-Child Facial Resemblance Measure}

Perceived parent-child facial resemblance was measured by $\mathrm{Yu}$ et al Perceived Parent-Children Facial Resemblance Scale. ${ }^{13}$ There were four items in this scale: "In your opinion, how much do you look like your father?", "In your opinion, how much do you look like your mother?", "In your friends' or family members' views, how much do you look like your father?" and "In your friends' or family members' views, how much do you look like your mother?". The scale was rated on a 10-point Likert scale, ranging from 1 (not at all) to 10 (completely). The correlation between the two items that assessed the perceived father-child facial resemblance was 0.81 , and the correlation between the two items that measured the perceived mother child facial resemblance was 0.87 .

\section{Parenting Style Measure}

The shortened EMBU was adopted to measure parenting style, which was revised by Arrindell et al. ${ }^{46}$ Jiang et al further revised the questionnaire in the context of Chinese culture. ${ }^{47}$ The questionnaire contained three dimensions: rejection (6 items, such as "Father/mother often treats me in an embarrassing way", "Father/mother often punishes me more than I could accept", etc.), emotional warmth ( 7 items, such as "father/mother praises me", "father/mother always tries to encourage me to become a leader", etc.) and over-protection (8 items, such as "father/mother always decides what I should wear or dress up", "I feel that my father/mother interferes with anything I do", etc.). The scale was rated on a 4-point scale, ranging from 1 (never) to 4 (always). Jiang et al demonstrated that the scale had good reliability and validity. ${ }^{47}$ Following the practice of prior research, ${ }^{48}$ Liu et al conducted a principal component analysis of the established parenting style structure and found two higher-order factors: caring and control. ${ }^{49}$ The emotional warmth was mainly loaded on the caring factor, while the parents' over-protection and rejection were mainly dependent on the control factor. To compare the parents' version to the children's version of the parenting style, this study used the structure proposed by Liu et al. ${ }^{50}$ In this study, the Cronbach's $\alpha$ coefficients of the caring dimension and control dimension of the scale were 0.66 and 0.73 (father), 0.59 and 0.75 (mother) respectively. The split-half reliability coefficients were 0.69 and 0.72 (father), 0.64 and 0.80 (mother) respectively.

\section{Academic Performance Measure}

Academic achievement was accessed by a single item "Where do you rank your academic performance in your class?". It was rated on a 5- point scale, with " $1=$ top $20 \%$ ", " 2 = top $20 \%-40 \%$ ", "3 = top $40 \%-60 \%$ ", "4 = top $60 \%-80 \%$ ", and " $5=$ bottom $20 \%$ ". And the rating score was reversed, the higher the score, the more excellent one is in terms of the academic performance. Previous studies have demonstrated students' self-reported academic ranks were highly consistent with official records of their academic performance. Self-report could reflect their true academic achievement. ${ }^{51,52}$

\section{Demographic Variables Measure}

Participants' demographic information were gathered, including participants' sex, participants' age, parents' education, perceived family economic status, and number of siblings in their families.

\section{Procedure}

First, the researcher mailed the questionnaires to the research assistant. Second, the research assistant distributed the questionnaire to the students and requested them to finish the questionnaire based on their own perceptions. Finally, the students submitted the completed questionnaire to the research assistant, who then returned the questionnaires to the investigator afterwards. 
Parental informed consent was obtained for all participants in the study.

\section{Data Analysis}

The software SPSS 19.0 was used for the data analysis. First, the overall data was performed in a correlation analysis. Second, a stepwise regression analysis was used to explore the moderation of parent sex on the relationship between the perceived parent-child facial resemblance and academic performance. Finally, a mediation effect test was adopted to explore the mediating effect of the father's caring parenting style on the relationship between perceived father-child facial resemblance and child's academic performance.

The missing data was handled with the List wise method. Harman's single factor test was used to test the common method bias. ${ }^{53}$ The results showed that the first factor explained by the unrotated and rotated variables were $18.56 \%$ and $13.38 \%$. Both were below the critical $40 \%$ threshold. Therefore, the common method bias effect was not significant in this study.

Besides, since the sample size was not calculated before the current study, G-Power software was used to conduct post hoc power analysis. ${ }^{54,55}$

\section{Results}

\section{Descriptive Analysis}

As shown in Table 1, the father-child facial resemblance, rather than mother-child facial resemblance, correlated with child's academic performance significantly. Besides, the father-child facial resemblance significantly correlated with the caring factor in the father's parenting style, and the caring factor in father's parenting style correlated with the academic performance significantly. Consist with the hypotheses, neither the relationship between father control parenting and father-child facial resemblance nor the relationship between mother control parenting and motherchild facial resemblance was not significant, thus, the control parenting was not concerned in the regression analysis.

\section{Moderation of Parents' Sex}

A stepwise regression analysis was conducted, with perceived father-child facial resemblance being the predictor, child's academic performance being outcome variable, and participants' sex, age, parents' education, perceived family economic status, number of siblings being the control

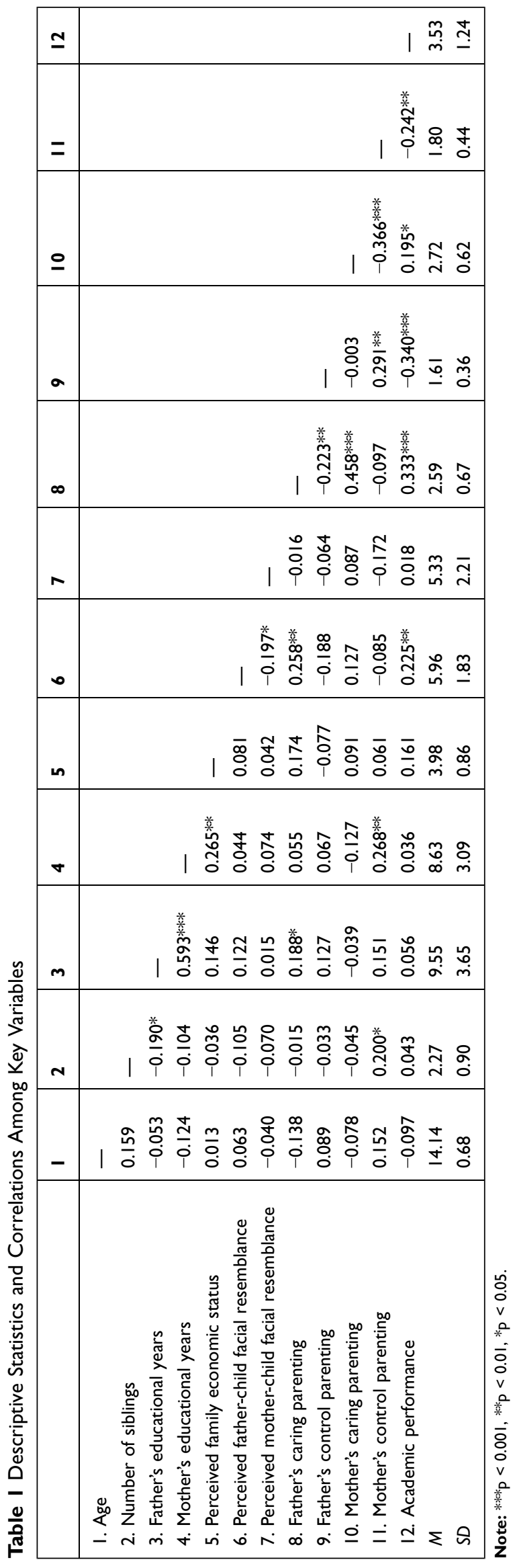


variables. As shown in Table 2, perceived father-child facial resemblance significantly predicted child's academic performance. The post-hoc power analysis showed that 1 $\beta$ was 0.96 , indicating that the effects in the current study can be significantly detected.

In the same way, a multiple regression analysis was performed to investigate the effect of perceived motherchild facial resemblance on the child's academic performance. As shown in Table 3, the effect of perceived mother-child facial resemblance is not significant.
Following Yu et al and Sun suggestion, a $t$-test [The t-test was conducted by the formula $t=\left(B_{1}-B_{2}\right) / \operatorname{sqrt}\left(\left(S E B_{1} * S E B_{1}\right.\right.$ $\left.\left.*\left(d f_{1}-1\right)+S E B_{2} * S E B_{2} *\left(d f_{2}-1\right)\right) /\left(d f_{1}+d f_{2}-2\right)\right)$. NOTE: $B_{1}$ is the unstandardized regression coefficient of Perceived father -child facial resemblance on the father-child closeness, the $S E B_{1}$ is the standard error of $B_{1}, d f_{1}$ is the freedom degree of the $B_{1} ; B_{2}$ is the unstandardized regression coefficient of Perceived mother-child facial resemblance on the motherchild closeness, the $S E B_{2}$ is the standard error of $B_{2}$, and $d f_{2}$ is the freedom of the $B_{2}$.] was conducted to explore the

Table 2 The Effect of Perceived Father-Child Facial Resemblance on Academic Performance

\begin{tabular}{|c|c|c|c|c|c|c|c|c|}
\hline \multirow[t]{3}{*}{ Predictive Variable } & \multicolumn{8}{|c|}{ Outcome Variable: Academic Performance } \\
\hline & \multicolumn{4}{|c|}{ Model I } & \multicolumn{4}{|c|}{ Model 2} \\
\hline & B & $S E_{B}$ & $t$ & $\mathbf{p}$ & B & $S E_{B}$ & $T$ & $\mathbf{p}$ \\
\hline Intercept & 3.323 & 2.757 & 1.206 & 0.231 & 2.787 & 2.700 & 1.032 & 0.304 \\
\hline Sex & 0.304 & 0.255 & 1.190 & 0.237 & 0.358 & 0.250 & 1.430 & 0.156 \\
\hline Age & -0.103 & 0.182 & -0.568 & 0.571 & -0.129 & 0.178 & -0.727 & 0.469 \\
\hline Number of siblings & 0.074 & 0.135 & 0.550 & 0.584 & 0.102 & 0.132 & 0.770 & 0.443 \\
\hline Father's education & 0.017 & 0.034 & 0.488 & 0.627 & 0.006 & 0.034 & 0.168 & 0.867 \\
\hline $\begin{array}{l}\text { Perceived family economic } \\
\text { status }\end{array}$ & 0.220 & 0.137 & 1.603 & 0.112 & 0.202 & 0.134 & 1.508 & 0.135 \\
\hline$R^{2}$ & \multicolumn{8}{|l|}{0.052} \\
\hline $\begin{array}{l}\text { Perceived father-child facial } \\
\text { resemblance }\end{array}$ & & & & & 0.157 & 0.063 & 2.492 & 0.014 \\
\hline $\begin{array}{l}R^{2} \\
\Delta R^{2}\end{array}$ & & & & & \multicolumn{2}{|c|}{$\begin{array}{l}0.105^{*} \\
0.053^{*}\end{array}$} & & \\
\hline
\end{tabular}

Note: ${ }^{*} p<0.05$.

Table 3 The Effect of Perceived Mother-Child Facial Resemblance on Academic Performance

\begin{tabular}{|c|c|c|c|c|c|c|c|c|}
\hline \multirow[t]{3}{*}{ Predictive Variable } & \multicolumn{8}{|c|}{ Outcome Variable: Academic Performance } \\
\hline & \multicolumn{4}{|c|}{ Model I } & \multicolumn{4}{|c|}{ Model 2} \\
\hline & B & $S E_{B}$ & $t$ & $\mathbf{p}$ & B & $S E_{B}$ & $T$ & $\mathbf{P}$ \\
\hline Intercept & 3.602 & 2.764 & 1.303 & 0.195 & 3.438 & 2.824 & 1.218 & 0.226 \\
\hline Sex & 0.332 & 0.254 & 1.308 & 0.194 & 0.345 & 0.258 & 1.336 & 0.184 \\
\hline Age & -0.109 & 0.182 & -0.598 & 0.551 & -0.104 & 0.183 & -0.570 & 0.570 \\
\hline Number of siblings & 0.058 & 0.132 & 0.441 & 0.660 & 0.060 & 0.133 & 0.451 & 0.653 \\
\hline Mother's education & -0.019 & 0.042 & -0.450 & 0.653 & -0.020 & 0.043 & -0.480 & 0.632 \\
\hline $\begin{array}{l}\text { Perceived family economic } \\
\text { status }\end{array}$ & 0.248 & 0.140 & 1.769 & 0.080 & 0.248 & 0.141 & 1.759 & 0.081 \\
\hline$R^{2}$ & \multicolumn{8}{|l|}{0.053} \\
\hline $\begin{array}{l}\text { Perceived mother-child facial } \\
\text { resemblance }\end{array}$ & & & & & 0.017 & 0.054 & 0.315 & 0.753 \\
\hline $\begin{array}{l}R^{2} \\
\Delta R^{2}\end{array}$ & & & & & \multicolumn{2}{|c|}{$\begin{array}{l}0.053 \\
0.000\end{array}$} & & \\
\hline
\end{tabular}


moderating effect of parents' sex on the relationship between the perceived parent-child facial resemblance and child's academic performance. ${ }^{38,56}$ Results showed that the effect of perceived father-child facial resemblance on the child's academic performance was significantly higher than the effect of perceived mother-child facial resemblance, $t$ (222) $=2.39, p<0.05$, Cohen's $d=0.32$. These findings attest to the hypothesis that parents' sex would moderate the relationship between the perceived parent-child facial resemblance and child's academic performance.

\section{Mediation of Caring Parenting Style}

We adopted the model 4 of PROCESS macro to examine the mediating effect of father's caring parenting on the association between the perceived father-child facial resemblance and child's academic performance. We used the perceived father-child facial resemblance as an independent variable, academic performance as a dependent variable, care parenting as a mediator, and the participants' sex, age, parents' education, perceived family economic status, and the number of siblings as control variables. As shown in Figure 2, while controlling for the sex, age, number of siblings, father's education, and the perceived family economic status, the perceived father-child facial resemblance significantly predicted the academic performance. However, when the father's caring parenting style enters the equation, the effect of the perceived father-child facial resemblance on child's academic performance was reduced to non-significant. The mediation effect Sobel test was significant, $z=1.98, p<0.05,95 \%$ bootstrap $\mathrm{CI}=$ $[0.011,0.127]$, not including zero. Notably, the mediation effect accounted for $38.1 \%$ of the total effect (see
Figure 2). Thus, father's caring parenting style fully mediated the relationship between the perceived fatherchild facial resemblance and child's academic performance.

\section{Discussion}

This study demonstrated that the perceived father-child facial resemblance could affect child's academic performance and this effect was accounted for by the father's caring parenting, which not only supported the paternal uncertainty hypothesis ${ }^{4,5,7,12,13}$ but also extended the parental investment theory. ${ }^{2,5,14}$

This research collected data from the monogamous family. Consistent with the previous study in a polygynous human population of rural Senegal, ${ }^{4}$ paternal investment was positively related to the father-child facial resemblance. Due to the female infidelity, the probability of paternity can vary among children. ${ }^{57}$ Fathers need adjust the paternal investment, because they may invest a child who did not have any relationship with them. The evolution in response to paternity uncertainty make them seek cues that characterize their genetic identity, such as, facial resemblance, ${ }^{4,5}$ body odor resemblance. ${ }^{4}$ Fathers tend to adjust resource investment on the children according to the degree of father-child facial resemblance, $4,7,58$ which further affects the development of children. $4,5,13,24,25$

The present study found that the perceived father-child facial resemblance could affect child's academic performance through the pathway of the father's caring parenting style. This is consistent with the previous findings showing that perceived father-child facial resemblance significantly predicted the physiological development of

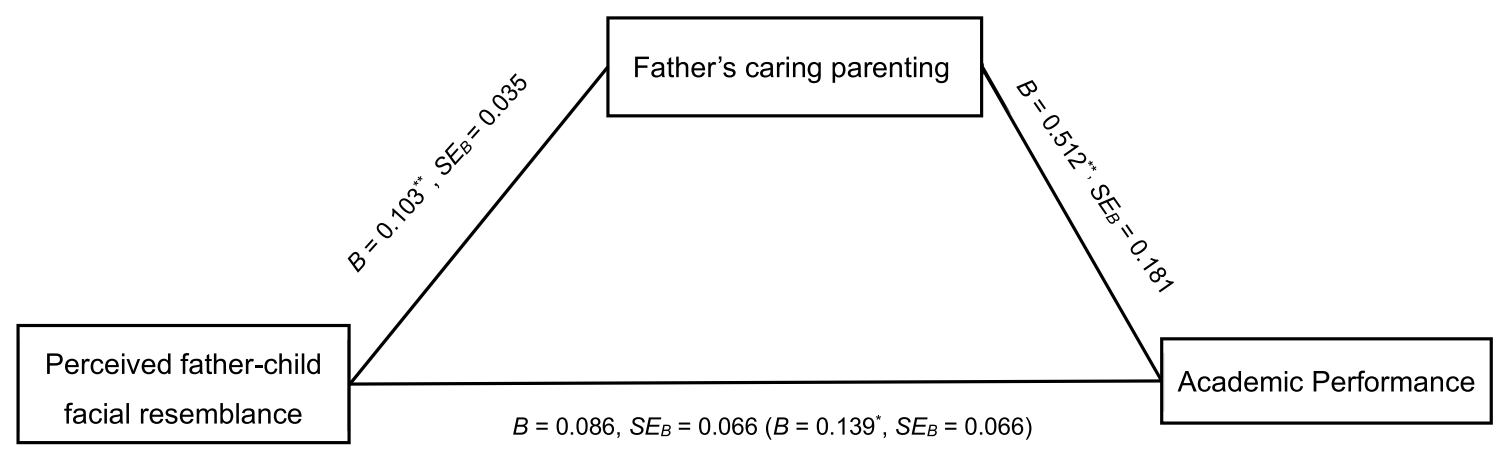

Notes: $\quad * * \mathrm{p}<.01, * \mathrm{p}<.05$

Figure 2 The mediating effect of father's care parenting between the perceived father-child facial resemblance and academic performance. 
the offspring in the primitive tribes of Senegal. ${ }^{4}$ However, when Alvergne replicated her study in France, the influence of perceived father-child facial resemblance on child's physiological development was not significant. ${ }^{5}$ Alvergne et al argued that in the developed countries, even though fathers did not invest much on their children, the mothers' investment was sufficient for the healthy development of the offspring. ${ }^{5}$

While Alvergne et al studies showed that father's material investment could be substituted by mother's material resources, ${ }^{5}$ this study focused on the father's emotional investment, which might not be substituted by mother's emotional support. Ryan, Martin, and BrooksGunn found that children who received more support from fathers scored higher in mental developmental index. ${ }^{59}$ Other researchers found that children could be braver when encountering challenges in life due to the fathers' caring and support. ${ }^{60,61}$ Even though the current participants were recruited in an economically developed city, this study still found that the fathers "caring parenting mediated the effect of perceived father-child facial resemblance on child"s academic development. In a word, the effect of perceived father-child facial resemblance on offspring's survival and growth through emotional investment were stronger and more stable than through material investment.

Although this study found that father-child facial resemblance can significantly affect the father's parenting style, the effect is still low. As shown in Table 3, the facial similarity between father and child can only explain 5.3\% variation of father's caring parenting style. In addition, father's caring parenting style may also be affected by other factors, no matter from the father's perspective or the children. Eg, the father's personality, ${ }^{62}$ social class, ${ }^{17}$ cultural background, ${ }^{63}$ father's relationship with mother, ${ }^{64}$ the child's personality ${ }^{65}$ and physical health, ${ }^{57}$ etc. Therefore, the results of this study should be treated rationally and objectively.

It is noting that this research demonstrated greater parental care and lower control related with adolescent higher academic performance, which was in line with results conducted in the previous studies. ${ }^{66-68}$ In fact, the benefits of greater caring are found both in the Eastern Culture ${ }^{69-71}$ and in the Western Culture. ${ }^{27,72}$ However, this research found parental control had a negative impact on the academic performance, which is inconsistent with some previous studies in Eastern Culture. ${ }^{69-71}$ Chao found that Chinese American adolescents from strictness without warmth families reported the better academic achievement. ${ }^{69}$ And some studies, conducted in China, found that both warmth and control are beneficial and more conducive to improving children's academic performance. ${ }^{70,71}$ Maybe, the different definition of the parental control could account for the controversy. As suggested by Liu et $\mathrm{al}^{49}$ the present study referred the control parenting as parents' neglect and rejection, which has a negative correlation with the academic performance. ${ }^{24,72}$ However, previous studies consider the control dimension as strictness, which reflects the parental attention to the child and their behavior norms. ${ }^{57,72}$ Many studies demonstrated that the strictness could promote children's academic performance in the Chinese cultural context. $^{69-71}$ Thus, the controversy was not essential.

Although this study provided consistent evidence for our hypotheses, there were several limitations. First, the self-reported academic performance could be susceptible to social desirability biases, such as the self-serving bias, even though past literatures have reported adequate validity and reliability. ${ }^{51,52}$ For example, participants' mean self-reported rank was 3.53 in the present sample, which was significantly higher than the mid-point (3.0), $t=4.61$, $p<0.001$. Thus, future research may use the objective indicators, such as GPA (grade point average), rather than the self-reported performance in validating the relationship between the father-child facial resemblance and child's academic achievement. Second, the current study adopted a cross-sectional design, which had a natural deficiency to deduce the causal relationship between independent variable and dependent variable, this study posited that father's caring parenting mediated the relationship between father-child facial resemblance and academic performance, however, there is a possible alternative explanation: offspring perceived themselves more look like his or her father when the offspring imitate with his or her father, thus, further study could use a longitudinal approach to enhance the internal validity. Third, due to the change of the adolescent self-concept ${ }^{73}$ and the greater need for bonding with friends, ${ }^{29}$ parental influence to adolescent declined while peer influence increased. ${ }^{74}$ Although the parenting style is still important for adolescent academic performance, future studies should consider the peer influence as a control variable. Finally, child's academic achievement is highly valued in Asian culture since it represented the honor of the whole family. ${ }^{75}$ For other countries and regions with different cultural backgrounds, the influence of perceived parent-child facial resemblance on child's academic performance may not 
hold. Thus, future studies could adopt different countries and ethnic groups to explore the potential influence of culture on the relationship between the perceived fatherchild facial resemblance and child's academic achievement.

\section{Conclusion}

This study explored the relationship between the perceived parent-child facial resemblance and child's academic performance. Those results showed that the perceived father-child facial resemblance rather than the perceived mother-child facial resemblance influenced the child's academic achievement, and this effect could be explained by the father's caring parenting style. These findings not only corroborated the paternal uncertainty hypothesis but also extended the parental investment theory.

\section{Ethics}

The present study received approval from the psychological research ethics committee of the Faculty of HumanEnvironment Studies at Beijing Normal University (16JJD880007).

\section{Parental Informed Consent}

Parental informed consent was obtained for all participants under the age of 18, in accordance with the Declaration of Helsinki.

\section{Acknowledgments}

This research was supported by a grand from the Research Program Funds of the Collaborative Innovation Center of Assessment toward Basic Education Quality (2019-04020BZPK01), a research funds for Key Laboratory of Adolescent Cyberpsychology and Behavior(CCNU), Ministry of Education (2018B01), a grand from the Postdoctoral Science Foundation of China (2019M652679), a grand from the Fundamental Research Funds for the Central Universities (CCNU18ZDPY07), and a grand from the selfdetermined research funds of CCNU from the colleges' basic research and operation of MOE (CCNU19TD018).

\section{Disclosure}

The authors report no conflicts of interest in this work.

\section{References}

1. Buss D. Evolutionary Psychology: The New Science of the Mind. Psychology Press; 2015.
2. Trivers R. Parental Investment and Sexual Selection. Sexual Selection\&the Descent of Man. New York: Aldine de Gruyter; 1972:136-179.

3. Platek SM, Critton SR, Burch RL, et al. How much paternal resemblance is enough? Sex differences in hypothetical investment decisions but not in the detection of resemblance. Evol Human Behav. 2003;24(2):81-87. doi:10.1016/S1090-5138(02)00117-4

4. Alvergne A, Faurie C, Raymond M. Father-offspring resemblance predicts paternal investment in humans. Anim Behav. 2009;78 (1):61-69. doi:10.1016/j.anbehav.2009.03.019

5. Alvergne A, Faurie C, Raymond M. Are parents' perceptions of offspring facial resemblance consistent with actual resemblance? Effects on parental investment. Evol Human Behav. 2010;31 (1):7-15. doi:10.1016/j.evolhumbehav.2009.09.002

6. Bressan P, Bertamini M, Nalli A, et al. Men do not have a stronger preference than women for self-resemblant child faces. Arch Sex Behav. 2009;38(5):657-664. doi:10.1007/s10508-008-9350-0

7. Apicella CL, Marlowe FW. Perceived mate fidelity and paternal resemblance predict men's investment in children. Evol Human Behav. 2004;25(6):371-378. doi:10.1016/j.evolhumbehav.2004.06.003

8. Billingsley J, Antfolk J, Santtila P, et al. Cues to paternity: do partner fidelity and offspring resemblance predict daughter-directed sexual aversions? Evol Human Behav. 2018;39(3):290-299. doi:10.1016/j. evolhumbehav.2018.02.001

9. Flinn MV. Mate guarding in a Caribbean village. Ethol Sociobiol. 1988;9(1):1-28. doi:10.1016/0162-3095(88)90002-7

10. Arantes J, Berg ME. Kinship recognition by unrelated observers depends on implicit and explicit cognition. Evol Psychol. 2012;10 (2):210-224. doi:10.1177/147470491201000204

11. Bressan P, Dal Martello MF. Talis pater, talis filius: perceived resemblance and the belief in genetic relatedness. Psychol Sci. 2002;13 (3):213-218. doi:10.1111/1467-9280.00440

12. Chang L, Lu HJ, Lee LNY, et al. Patrilocal residence and father-child resemblance beliefs in relation to paternal investment. Parenting. 2010;10(4):274-285. doi:10.1080/15295192.2010.492039

13. Yu Q, Zhang Q, Jin S, et al. The effect of perceived facial resemblance on parent-child relationship. Pers Individ Dif. 2017;116:359-365. doi:10.1016/j.paid.2017.05.016

14. Hamilton WD. The genetical evolution of social behaviour II. $J$ Theor Biol. 1964;7(1):17-52. doi:10.1016/0022-5193(64)90039-6

15. Belsky J. Childhood experience and the development of reproductive strategies. Acta Psychologica Sinica. 2010;22(1):28-34.

16. Simpson JA, Belsky J. Attachment Theory Within a Modern Evolutionary Framework. 2008, Guilford Press:131-157.

17. Geary DC. Evolution of paternal investment. In: Buss DM, editor. The Handbook of Evolutionary Psychology. 2016, John Wiley \& Sons:524-541.

18. Daly M, Wilson M. Whom are newborn babies said to resemble? Ethol Sociobiol. 1982;3(2):69-78. doi:10.1016/0162-3095(82)90002-4

19. McLain DK, Setters D, Moulton MP, et al. Ascription of resemblance of newborns by parents and nonrelatives. Evol Human Behav. 2000;21(1):11-23. doi:10.1016/S1090-5138(99)00029-X

20. Daly M, Wilson M. The Evolutionary Social Psychology of Family Violence. Handbook of Evolutionary Psychology: Ideas, Issues Applications. 1998, Psychology Press:431-456.

21. Bressan P, Kramer P. Human kin detection. Wiley Interdiscip Rev Cogn Sci. 2015;6:299-311.

22. Apicella CL, Marlowe FW. Men's reproductive investment decisions - Mating, parenting, and self-perceived mate value. Human Nat. 2007;18(1):22-34.

23. Pinquart M. Associations of general parenting and parent-child relationship with pediatric obesity: a meta-analysis. J Pediatr Psychol. 2014;39(4):381-393. doi:10.1093/jpepsy/jst144

24. Yu Q, Zhang Q, Xiong Q, et al. The more similar, the more warmth: the effect of parent-child perceived facial resemblance on parenting behavior. Pers Individ Diff. 2019;138:358-362. doi:10.1016/j. paid.2018.10.027 
25. Sear R, Mace R. Who keeps children alive? A review of the effects of kin on child survival. Evol Human Behav. 2008;29(1):1-18. doi:10.1016/j.evolhumbehav.2007.10.001

26. Baumrind D. Current patterns of parental authority. Dev Psychol. 1971;4(1p2):1. doi:10.1037/h0030372

27. Maccoby E. Socialization in the context of the family: parent-child interaction. Handbook Child Psychol. 1983;4:1-101.

28. García F, Serra E, Garcia O, et al. A third emerging stage for the current digital society? Optimal parenting styles in Spain, the United States, Germany, and Brazil. Int $J$ Environ Res Public Health. 2019;16(13):2333. doi:10.3390/ijerph16132333

29. Gallarin M, Torres-Gomez B, Alonso-Arbiol I. Aggressiveness in adopted and non-adopted teens: the role of parenting, attachment security, and gender. Int J Environ Res Public Health. 2021;18 (4):2034. doi:10.3390/ijerph18042034

30. Turner EA, Chandler M, Heffer RW. The influence of parenting styles, achievement motivation, and self-efficacy on academic performance in college students. J Coll Stud Dev. 2009;50(3):337-346. doi:10.1353/csd.0.0073

31. Ishak Z, Low SF, Lau PL. Parenting style as a moderator for students' academic achievement. J Sci Educ Technol. 2012;21(4):487-493. doi:10.1007/s10956-011-9340-1

32. Heaven PC, Ciarrochi J. Parental styles, conscientiousness, and academic performance in high school: a three-wave longitudinal study. Pers Soc Psychol Bull. 2008;34(4):451-461. doi:10.1177/ 0146167207311909

33. Cassidy J, Shaver PR. Handbook of Attachment: Theory, Research, and Clinical Applications. Rough Guides; 2002.

34. O'Connor MC, Paunonen SV. Big five personality predictors of post-secondary academic performance. Pers Individ Diff. 2007;43 (5):971-990. doi:10.1016/j.paid.2007.03.017

35. DeBruine LM. Facial Resemblance Enhances Trust. Proc Biol Sci. 2002;269(1498):1307-1312. doi:10.1098/rspb.2002.2034

36. DeBruine LM. Trustworthy but not lust-worthy: context-specific effects of facial resemblance. Pro $R$ Soc $B$. 2005;272 (1566):919-922. doi:10.1098/rspb.2004.3003

37. Weinberg SM, Parsons TE, Marazita ML, Maher BS. Heritability of face shape in twins: a preliminary study using 3D stereophotogrammetry and geometric morphometrics. Dentistry. 2013;1(1):7-11.

38. Wiszewska A, Pawłowski B, Boothroyd L. Father-daughter relationship as a moderator of sexual imprinting: a Facialmetric Study. Evol Human Behav. 2007:28:248-252.

39. Maloney LT, Dal Martello MF. Kin recognition and the perceived facial similarity of children. $J$ Vis. 2006;6(10):4. doi:10.1167/6.10.4

40. Yu Q, Zhang Q, Chen J, et al. The effect of perceived parent-child facial resemblance on parents' trait anxiety: the moderating effect of parents' gender. Front Psychol. 2016;7:658. doi:10.3389/fpsyg.20 16.00658

41. Alvergne A, Faurie C, Raymond M. Differential facial resemblance of young children to their parents: who do children look like more? Evol Human Behav. 2007;28(2):135-144. doi:10.1016/j. evolhumbehav.2006.08.008

42. Pong S, Hao L, Gardner E. The roles of parenting styles and social capital in the school performance of immigrant Asian and Hispanic adolescents. Soc Sci Q. 2005;86(4):928-950. doi:10.1111/j.00384941.2005.00364.x

43. Pinquart M. Associations of parenting styles and dimensions with academic achievement in children and adolescents: a meta-analysis. Educ Psychol Rev. 2016;28(3):475-493. doi:10.1007/s10648-0159338-y

44. Kim SH, Bal VH, Lord C. Longitudinal follow-up of academic achievement in children with autism from age 2 to 18 . J Child Psychol Psychiatry. 2018;59(3):258-267. doi:10.1111/jcpp.12808

45. Spera C. A review of the relationship among parenting practices, parenting styles, and adolescent school achievement. Educ Psychol Rev. 2005;17(2):125-146. doi:10.1007/s10648-005-3950-1
46. Arrindell W, Sanavio E, Aguilar G, et al. The development of a short form of the EMBU: its appraisal with students in Greece, Guatemala, Hungary and Italy. Pers Individ Dif. 1999;27:613-628. doi:10.1016/ S0191-8869(98)00192-5

47. Jiang J, Lu ZR, Jiang BJ, Xu Y. Revision of the short-form egna minnen av barndoms uppfostran for Chinese. Psychol Develop Educ. 2010;V26:94-99.

48. Markus M, Lindhout IE, Boer F, et al. Factors of perceived parental rearing styles: the EMBU-C examined in a sample of Dutch primary school children. Pers Individ Dif. 2003;34(3):503-519. doi:10.1016/ S0191-8869(02)00090-9

49. Liu F, Cheng X, Gong HL. The effect of parenting styles on child's later anxiety: cognitive emotion regulation strategies and masculinity play the role of mediator. Psychol Sci. 2011;6:1390-1396.

50. Liu Y, Su L, Wang H. Women's cue preferences and information processing mode in mate choice. Acta Psychologica Sinica (Chinese). 2011;43(01):21-29. doi:10.3724/SP.J.1041.2011.00021

51. Gray EK, Watson D. General and specific traits of personality and their relation to sleep and academic performance. J Pers. 2002;70 (2):177-206. doi:10.1111/1467-6494.05002

52. Lee KM, Jones MK, Day SX. The impact of academic competency teasing and self-concept on academic and psychological outcomes among gifted high school students. Learning Individ Diff. 2017;56:151-158. doi:10.1016/j.lindif.2016.10.020

53. Podsakoff PM, MacKenzie SB, Lee J-Y, et al. Common method biases in behavioral research: a critical review of the literature and recommended remedies. $J$ Appl Psychol. 2003;88(5):879. doi: 10.1037/0021-9010.88.5.879

54. Faul F, Erdfelder E, Lang A-G, et al. G*Power 3: a flexible statistical power analysis program for the social, behavioral and biomedical sciences. Behavior Research Methods. 2007;39(2):175-191. doi:10.3758/BF03193146

55. Perugini M, Gallucci M, Costantini G. A practical primer to power analysis for simple experimental designs. Int Rev Soc Psychol. 2018:9:31.

56. Sun Z. Medical Statistics. People's Medical Publishing House(PMPH); 2010.

57. Westneat DF, Sherman PW. Parentage and the evolution of parental behavior. Behav Ecol. 1993;4(1):66-77.

58. Heijkoop M, Dubas JS, van Aken MAG. Parent-child resemblance and kin investment: physical resemblance or personality similarity? Eur J Develop Psychol. 2009;6(1):64-69. doi:10.1080/17405620802642306

59. Ryan RM, Martin A, Brooks-Gunn J. Is one good parent good enough? Patterns of mother and father parenting and child cognitive outcomes at 24 and 36 months. Parenting. 2006;6(2-3):211-228.

60. Paquette D. Theorizing the father-child relationship: mechanisms and developmental outcomes. Hum Dev. 2004;47(4):193-219. doi:10. $1159 / 000078723$

61. Yarrow LJ, MacTurk RH, Vietze PM, et al. Development course of parental stimulation and its relationship to mastery motivation during infancy. Devlop Psychol. 1984;20(3):492.

62. Corpuz R. Paternal Investment in Humans. In: V.A.W- S. T.K. Shackelford, editor. Encyclopedia of Evolutionary Psychological Science. 2016. Springer.

63. Gray P, Anderson K. Fatherhood: Evolution and Human Paternal Behavior. Bibliovault OAI Repository, the University of Chicago Press; 2011.

64. Kaplan H, Lancaster J, Anderson K. Human Parental Investment and Fertility: The Life Histories of Men in Albuquerque. In: Alan Booth, Ann C. Crouter, editor. Men in Families: When Do They Get Involved? What Difference Does It Make? 1998.Lawrence Erlbaum Assoclates.

65. Rowe D. What Twin and Adoption Studies Reveal About Parenting: Influences on Academic, Intellectual, and Social-Emotional Development. In: John G. Borkowski, Sharon Landesma Ramey, Marie Bristol-Power, editor. Parenting and the Child's World.2001. Psychology Press:21-34. 
66. Gimenez-Serrano S, Garcia F, Garcia OF. Parenting Styles and Its Relations with Personal and Social Adjustment Beyond Adolescence: Is the Current Evidence Enough? European Journal of Developmental Psychology; 2021.

67. Martinez I, Murgui S, Garcia OF, Garcia F. Parenting and adolescent adjustment: the mediational role of family self-esteem. J Child Fam Stud. 2021;30(5):1184-1197. doi:10.1007/s10826-021-01937-z

68. Queiroz P, Garcia OF, Garcia F, Zacares JJ, Camino C. Self and nature: parental socialization, self-esteem, and environmental values in Spanish adolescents. Int J Environ Res Public Health. 2020;17 (3732):1-13. doi:10.3390/ijerph17103732

69. Chao RK. Extending research on the consequences of parenting style for Chinese Americans and European Americans. Child Dev. 2001;72 (6):1832-1843. doi:10.1111/1467-8624.00381

70. Yeung J. Family processes, parenting practices, and psychosocial maturity of Chinese youths: a latent variable interaction and mediation analysis. Int J Environ Res Public Health. 2021;18:4357. doi:10.3390/ijerph18084357

71. Yang J, Zhao X. Parenting styles and children's academic performance: evidence from middle schools in China. Child Youth Serv Rev. 2020;113:105017. doi:10.1016/j.childyouth.2020.105017
72. Lamborn SD, Mounts NS, Steinberg L, et al. Patterns of competence and adjustment among adolescents from authoritative, authoritarian, indulgent, and neglectful families. Child Dev. 1991;62(5):1049-1065. doi: $10.2307 / 1131151$

73. Chen F, Garcia OF, Fuentes MC, et al. Self-Concept in China: validation of the Chinese Version of the five-factor self-concept (AF5) questionnaire. Symmetry. 2020;12(5):798. doi:10.3390/sym 12050798

74. Garcia OF, Serra E, Zacares JJ, et al. Alcohol use and abuse and motivations for drinking and non-drinking among Spanish adolescents: do we know enough when we know parenting style? Psychol Health. 2020;35(6):645-664. doi:10.1080/08870446.20 19.1675660

75. Chao RK. Chinese and European American mothers' beliefs about the role of parenting in children's school success. J Cross Cult Psychol. 1996;27(4):403-423. doi:10.1177/0022022196274002
Psychology Research and Behavior Management

\section{Publish your work in this journal}

Psychology Research and Behavior Management is an international, peer-reviewed, open access journal focusing on the science of psychology and its application in behavior management to develop improved outcomes in the clinical, educational, sports and business arenas. Specific topics covered in the journal include: Neuroscience, memory and decision making; Behavior modification and management; Clinical

\section{Dovepress}

applications; Business and sports performance management; Social and developmental studies; Animal studies. The manuscript management system is completely online and includes a very quick and fair peer-review system, which is all easy to use. Visit http://www. dovepress.com/testimonials.php to read real quotes from published authors. 